ISSN 2073-445X

www.mdpi.com/journal/land/

Article

\title{
Landscape Dynamics on the Island of La Gonave, Haiti, 1990-2010
}

\author{
Justin White *, Yang Shao, Lisa M. Kennedy and James B. Campbell \\ Department of Geography, Virginia Tech, 115 Major Williams Hall, Blacksburg, VA 24061, USA; \\ E-Mails: yshao@vt.edu (Y.S.); kennedy1@vt.edu (L.M.K.); jayhawk@vt.edu (J.B.C.) \\ * Author to whom correspondence should be addressed; E-Mail: justin7@vt.edu; \\ Tel.: +1-540-231-6886; Fax: +1-540-231-2089.
}

Received: 17 July 2013; in revised form: 5 September 2013 / Accepted: 5 September 2013 /

Published: 16 September 2013

\begin{abstract}
The island of La Gonave lies northwest of Port-au-Prince and is representative of the subsistence Haitian lifestyle. Little is known about the land cover changes and conversion rates on La Gonave. Using Landsat images from 1990 to 2010, this research investigates landscape dynamics through image classification, change detection, and landscape pattern analysis. Five land cover classes were considered: Agriculture, Forest/Dense Vegetation (DV), Shrub, Barren/Eroded, and Nonforested Wetlands. Overall image classification accuracy was $87 \%$. Results of land cover change analysis show that all major land cover types experienced substantial changes from 1990 to 2010. The area percent change was $-39.7,-22.7,87.4$, and -7.0 for Agriculture, Forest/Dense Vegetation, Shrub, and Barren/Eroded. Landscape pattern analysis illustrated the encroachment of Shrub cover in core Forest/DV patches and the decline of Agricultural patch integrity. Agricultural abandonment, deforestation, and forest regrowth combined to generate a dynamic island landscape, resulting in higher levels of land cover fragmentation.
\end{abstract}

Keywords: tropical land cover change; La Gonave; Haiti; landscape pattern analysis; Landsat 5 (TM)

\section{Introduction}

Land use/cover change in tropical regions is widely accepted as an important component of global change [1-3]. It has received increasing attention over the past three decades, mainly because of the 
high rates of deforestation across broad geographic regions and related negative environment consequences for global carbon balance [4], biodiversity [5], water quality [6], soil erosion [6], and ecosystem services in general [7-9]. Previous tropical land cover change studies have mainly focused on a three-level approach summarized by [3,9]: (1) Using remote sensing image analysis or other geo-spatial techniques to characterize the rate and pattern of land cover change; (2) Conducting extensive case studies to obtain knowledge about local land cover dynamics; (3) Identifying the drivers of land cover change at a broader scale and developing land change simulations for possible future scenarios.

For some "hot spot" areas of the Amazon Basin, Southeast Asia, and Africa, long-term research sites have been established $[10,11]$. Some selected study sites have been treated as Near-Laboratory research areas to examine land cover dynamics, identify the drivers and consequences of land cover change, validate land change projections, and study human environmental interactions [11]. Despite these unprecedented advances, large uncertainties remain for all aspects of tropical land cover change studies [2]. Detailed land cover data, especially those related to multi-temporal land change at medium spatial resolution (e.g., $30 \mathrm{~m}$ ), are still unavailable for most tropical regions. Compared to "hot spots" such as Amazon Basin, small nations and regions of low forest cover have received much less attention, although they are equally important in improving our understanding of land cover dynamics and human-environment interactions.

With free access to the Landsat data archive and the ongoing Landsat Data Continuity Mission (LDCM), researchers can now obtain and derive multi-temporal land cover information for almost any region of the world. This capability would allow establishment of a large number of research sites, subsequent comparative studies would then be possible for generalizing theories and conclusions at broader geographic and temporal scales [2,12]. This paper focuses on the use of freely available Landsat data to characterize tropical land cover change on the largest offshore island of Haiti-the island of La Gonave. A review of recent remote sensing work shows that little previous land change research has been conducted for Haiti or its offshore islands.

Haiti has experienced rapid deforestation in the past and only $3 \%$ forest cover remains in the mainland [13]. Dolisca et al. [14] report that $85 \%$ of the Haitian population depends on biomass energy for domestic uses and 3.3 million $\mathrm{m}^{3}$ of fuelwood is used per year. As forest resources on the mainland are exhausted, the island of La Gonave becomes one of the major producers of biomass energy. Extensive deforestation of $\mathrm{La}$ Gonave can be directly linked to increased demand for charcoal [15]. The consequences of deforestation are amplified by high topographic relief and variable, bimodal annual precipitation patterns. The loss of land productivity through erosion is the main concern with regard to sustainability of island ecosystem, and human well-being. To date, government conservation policies for the island are largely non-existent. Other than a rough estimate of the total population $(\sim 80,000)$, there is little social, natural, or geographical information available for the island. It is unclear how the land cover has changed on La Gonave. It is notable that many tropical ecosystems can recover fast from extensive deforestation if the land is not extremely degraded.

We used the island of La Gonave as a case study to examine deforestation, agricultural land abandonment, forest regrowth, and their interactions. The overall objective of this research is to investigate how land cover changed on La Gonave, Haiti, 1990-2010. More specifically, this research aims to: (1) characterize major land cover types (shrub, forest/dense vegetation, agricultural land) and 
their change using Landsat images; (2) conduct an accuracy assessment of image classification through field validation and aerial photo interpretation; (3) and examine the landscape dynamics using landscape patterns metrics.

\section{Methods}

\subsection{Study Area}

La Gonave is an asymmetric anticline with its axis extending northwest to southeast almost parallel to the mainland shore (Figure 1) [16]. It spans $743 \mathrm{~km}^{2}$ and is located $51 \mathrm{~km}$ northwest of Port-au-Prince bordering the Canal de Saint-Marc to the northeast and the Canal du Sud to the south. Limestone forms the main geological component of La Gonave; however, there are darker, more iron rich soils in the highlands (reaching elevations of $778 \mathrm{~m}$ ). The island has a bimodal annual precipitation pattern [17,18]. The first rainy season lasts from April to June and the latter from August to October. One of the most important physical features of La Gonave is an uplifted ridge coinciding with the Gonave Island Anticline. To the northwest of the ridge is the Plaine des Mapou. This area is named for having mapou trees (though few stands remain on La Gonave today) and contains the most fertile soils on the island. This enclosed depression is about $5 \mathrm{~km}$ long, $1 \mathrm{~km}$ wide and is completely encircled by limestone ridges [16]. The entire site is used for agriculture.

Figure 1. Island of La Gonave (18 $\left.50^{\prime} 0^{\prime \prime} \mathrm{N}, 73^{\circ} 5^{\prime} 0^{\prime \prime} \mathrm{W}\right)$, Haiti, using Landsat 5 TM imagery, positioned in the Gulf of Gonave between Canal de Saint-Marc and Canal du Sud opening westward.

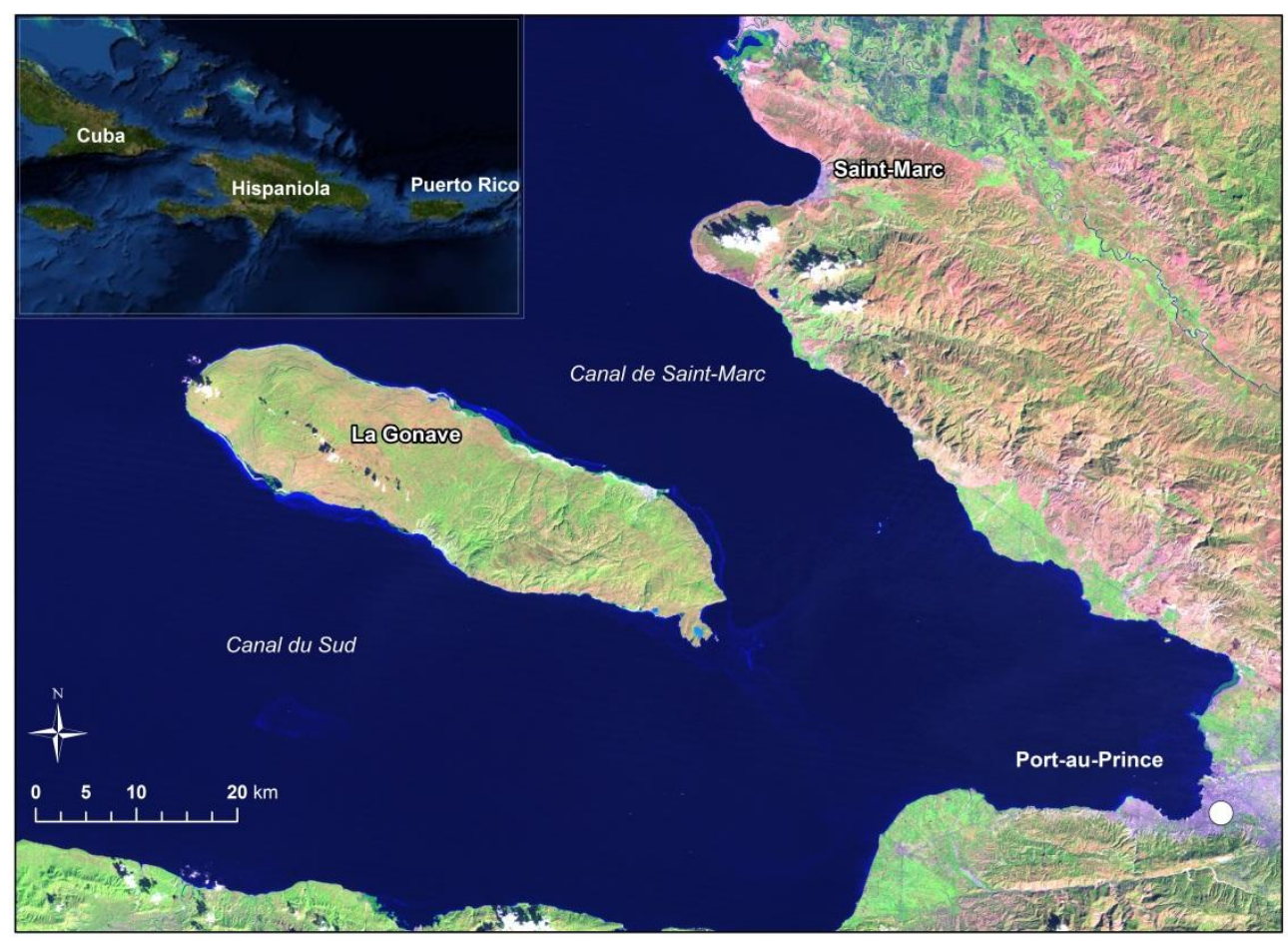

Charcoal production is one of the most common forms of employment for all ages on La Gonave. This includes the felling of timber (or woody shrubbery), burning, packing, and transport by chaloupe to the mainland for sale. La Gonave is a major producer of charcoal as the mainland was deforested 
earlier and more intensely than the island. Informal discussions with charcoal producers in resident villages revealed that they grew rice before it was internationally imported. The rice imports forced the local workers to find new occupations.

There is currently no environmental legislation enforced on La Gonave and it is common for the villages and the citizens to live unregistered with the federal government. The island's resident population has been declared from 75,548 [19] to 100,000 [20]. The names of many villages, as denoted by maps from the 1970s and 2000s, are unrecognized by their long term residents. This area is commonly neglected and has no extensive government medical post because of its physical, economic, and infrastructural isolation. Generators are supplied through aid packages, however fuel is unavailable and many of the generators have since deteriorated and been stripped of necessary parts. A localized cholera outbreak occurred on the island during a visit to the field site and palm water IV's were used to sustain ill individuals.

\subsection{Data}

All possible Landsat scenes for the study area were examined through the United States Geological Survey (USGS) Landsat Earth Resources Observation Systems (EROS) Data Center. Only a few images of the island were considered to be usable due to cloud cover. Landsat 7 produces the most recent cloud free imagery of the island; however, there are substantial data gaps caused by the operational failure of the Scan Line Corrector. A number of factors were considered in the process of image selection: anniversary dates, cloud cover, and surface moisture conditions. We determined late January to be the optimum time of year for image analysis. Data acquired from this time had the least annual cloud cover and evapotransitive moisture levels. Two Landsat 5 TM images collected on 22 January 1990 and 29 January 2010 were obtained for image classification and change-detection analysis. These dates lie at the center of the dry season and help minimize effects of seasonal variability. The Landsat images were pre-processed by the USGS to standard terrain correction (Level 1T). The 1990 Landsat image was registered to the 2010 image resulting in geometric registration error $<0.5$ pixel. There was no need to correct atmospheric effects since two images will be independently classified [21].

Aerial photos for this region were downloaded from the USGS Hazards Data Distribution Systems [22]. These natural color images were acquired in late January 2010 and were collected for monitoring and assessment of hazards and natural resources. The aerial photos have $30 \mathrm{~cm}$ spatial resolution, which is suitable for training area selection and the accuracy assessment associated with Landsat-based image classification.

\subsection{Image Classification and Accuracy Assessment}

Five primary land cover types were considered for each time period. These were based on a modified Anderson Classification Scheme [23,24] and include Agriculture, Forest/Dense Vegetation (DV), Shrub, Barren/Eroded, and Nonforested Wetlands. It is important to note that the Forest/Dense Vegetation class is composed of all vegetation growth levels beyond the shrub stage. Forest lands were considered to have a tree-crown areal density of $\sim 10 \%$ or more [23] (observed from aerial photos). These five classes fulfill the criteria of being mutually exclusive yet exhaustive of the land cover types 
in the study area [25]. Grassland was initially considered as an additional possible class, but it only covers a small portion of the island, thus it was excluded from further study. In total there was <2\% cloud cover. The Cloud and Shadow pixels were masked before the image classification and change detection process.

A supervised classification was conducted using the analyst's background knowledge of the study area. The training pixels for the $2010 \mathrm{TM}$ image were collected using $30 \mathrm{~cm}$ aerial photos as the primary reference. The sample size for each cover type ranged from about 130-11,700 pixels. For each land cover type, the training pixels chosen were spatially distributed across the island. The training samples for the 1990 image were selected using visual interpretation of the Landsat TM image since no aerial photos were available. A maximum likelihood classifier (ML) was used for the image classification. The ML was selected because it has been among the most commonly applied for remote sensing applications [26,27]. We used ERDAS IMAGINE 2010 to process the images.

For the 2010 classification, accuracy assessment was conducted using a combination of field validation and aerial photo interpretation. The validation data points were selected using a stratified random sample [28,29]. An average of 61 points per class were selected, with 55 as the lowest number, in agreement with the standards set by [25]. We conducted a field trip from May to June 2012 for GPS data collection and image classification verification. Points deemed inaccessible (due to rugged terrain) were later validated by overlaying the final classification maps atop the $30 \mathrm{~cm}$ resolution aerial photos. We evaluated the classification performances using standard error matrices and calculated Kappa coefficients.

\subsection{Change Detection and Spatial Pattern Analysis}

We selected a simple Post Classification Comparison (PCC) change detection for the land cover change analysis. PCC generates the "from-to" change classes, which are often needed when complete landscape change information is desired [30-32]. The success of the PCC method largely depends on the accuracies of the classified anniversary maps [32]. The error accumulation problem can seriously impact the change detection performance [30]. It should be noted that there are many other change detection techniques available: image differencing/ratioing, vegetation index differencing, multi-date classification, change vector analysis, and principal components analysis, we selected the PCC method mainly for its simplicity in deriving complete "from-to" change information.

Image classification and change detection provided general statistics (e.g., percentage of change) related to land cover change; however, the spatial structure of the land cover, organization, and dynamics need to be addressed using additional measures. In landscape ecology, landscape pattern indices have long been used to characterize spatial patterns of land use/cover types in both natural and urban systems [33-36]. Landscape pattern indices describe both the composition and structure of landscapes [33,34]. The spatial arrangement, position, and shape complexities of land cover can be linked to underlying human/natural processes [35]. This study used a number of landscape pattern indices to characterize the change of landscape. FRAGSTATS software [37] was used to calculate the following indices: total number of patches, the largest patch size, and mean patch size. There are hundreds of indices available, but we selected only from the most commonly used indices to characterize landscape dynamics. Habitat integrity is most effectively estimated by landscape metrics 
at the class-level $[38,39]$ in our study area. Therefore, the pattern indices selected were calculated at the land cover class level. The landscape pattern indices derived from 1990 to 2010 land cover maps were compared and reported. We also divided the island into 15 elevation strata (52 $\mathrm{m}$ increments) in order to measure land cover change rates based on elevation. Documenting the cover change rates by elevation creates additional baseline data to refine interpretation of spatial patterns of land cover conversion.

\section{Results}

\subsection{Assessment of Image Classification Accuracy}

For 2010 image classification, the overall accuracy was $87 \%(n=305)$ with a Kappa coefficient of 0.84 (Table 1). The accuracy of Forest/DV classification was the lowest at $71 \%$ and the shrub class contributed over $50 \%$ of commission error. The Landsat image was obtained during the dry season and the spectral signals of xeric tree species can be confused with the shrub class due to varying greenness levels. Due to the constant harvest of small woody plants for charcoal production, the forest landscape was highly fragmented, leading to complex spatial mixing of shrub and forest cover. Thus, the separation of Forest/DV and Shrub can be difficult, especially along the transition zone of shrub and forest land.

Table 1. Accuracy assessment for 2010 image classification.

\begin{tabular}{|c|c|c|c|c|c|c|c|c|}
\hline & \multicolumn{5}{|c|}{ Reference } & \multirow{2}{*}{ Total } & \multirow{2}{*}{ Correct (\%) } & \multirow{2}{*}{ Commission (\%) } \\
\hline & Ag & Forest & Shrub & Barren & Wetlands & & & \\
\hline Agriculture & 56 & 0 & 4 & 0 & 0 & 60 & 93 & 7 \\
\hline Forest/DV & 3 & 46 & 10 & 6 & 0 & 65 & 71 & 29 \\
\hline Shrub & 1 & 1 & 48 & 5 & 0 & 55 & 87 & 13 \\
\hline Barren/Eroded & 3 & 0 & 6 & 55 & 0 & 64 & 86 & 14 \\
\hline Nonforested Wetlands & 0 & 0 & 0 & 0 & 61 & 61 & 100 & \\
\hline Total & 63 & 47 & 68 & 66 & 61 & & \multicolumn{2}{|c|}{$(n=305)$} \\
\hline$\%$ Correct & 89 & 98 & 71 & 83 & 100 & & \multicolumn{2}{|c|}{ Overall $(\%)=87$} \\
\hline$\%$ Omission & 11 & 2 & 29 & 17 & 0 & & \multicolumn{2}{|c|}{ kappa $=0.84$} \\
\hline
\end{tabular}

The classification accuracy of agricultural land was the highest at 93\%. This level exceeded initial expectations and can be attributed to the distinct surface texture and unique locations where exposed soil contains higher levels of organic material. The shrub cover accounted for $100 \%$ of the commission error. Based on field notes, we determined that the error relates to the sparse grasses that persist in the dry season. Isolated large fruit-bearing trees that we observed in agricultural settings may also cause classification confusion. The Shrub class had high user's accuracy at $87 \%$, however, the corresponding producer's accuracy was the lowest (71\%) among all classes. The error was largely related with shrub-forest confusion. The Barren/Eroded class and wetland classes both had above $80 \%$ accuracy. It should be noted that human settlement or built-up area was included in the Barren/Eroded class, because the total built-up area only accounts for a very small percentage of the entire study area. We did not conduct an accuracy assessment for the 1990 image classification due to lack of reference data. 


\subsection{Land Cover Change and Conversion}

According to the 1990 image classification, area distribution of land cover classes was 79.96, 386.52, 140.13, and $42.25 \mathrm{~km}^{2}$ for Agricultural land, Forest/DV, Shrub, and Barren/Eroded, respectively. The land cover has endured many significant transitions over the 20 -year period. The area distribution in 2010 was measured to be $48.19,298.83,262.56$, and $39.27 \mathrm{~km}^{2}$ for these four respective land cover classes. These values corresponded to $-39.73 \%,-22.69 \%, 87.37 \%$, and $-7.04 \%$ of area change for individual classes (Table 2).

Table 2. Land cover class areas and rates of change for respective time periods.

\begin{tabular}{cccccc}
\hline Class & $\begin{array}{c}\text { 1990 Area } \\
\text { (ha) }\end{array}$ & $\begin{array}{c}\mathbf{2 0 1 0} \text { Area } \\
\text { (ha) }\end{array}$ & $\begin{array}{c}\text { 1990-2010 Area } \\
\text { Change (ha) }\end{array}$ & $\begin{array}{c}\text { 1990-2010 Area } \\
\text { Change (\%) }\end{array}$ & $\begin{array}{c}\text { Annual Rate } \\
\text { of Change }\end{array}$ \\
\hline Agriculture & $7,996.0$ & $4,819.0$ & $-3,177$ & -39.7 & -2.5 \\
Forest/DV & $38,652.1$ & $29,883.3$ & $-8,768.8$ & -22.7 & -1.3 \\
Shrub & $14,012.6$ & $26,255.7$ & $12,243.2$ & +87.4 & +3.2 \\
Barren/Eroded & $4,224.6$ & $3,927.2$ & -297.4 & -7.0 & -0.4 \\
\hline
\end{tabular}

Table 3 shows the change matrix for 1990-2010 expressed in percentages. Only $19.76 \%$ of agricultural land remained unchanged. The majority of 1990 agricultural lands were converted to shrub (45.01\%) and forest lands (34.23\%) during the time period. These conversions suggest a high level of agricultural land abandonment, as well as development of secondary vegetation.

Table 3. Land cover class conversion matrix from 1990 to 2010. Rows indicate the distribution $(\%)$ of class conversion.

\begin{tabular}{cccccc}
\hline & Ag2010 & Forest2010 & Shrub2010 & Barren2010 & Total \\
\hline Ag1990 & $\mathbf{1 9 . 7 6}$ & 34.23 & 45.01 & 1.00 & 100.00 \\
Forest/DV1990 & 7.31 & $\mathbf{6 2 . 5 2}$ & 27.47 & 2.70 & 100.00 \\
Shrub1990 & 2.65 & 15.07 & $\mathbf{7 5 . 1 7}$ & 7.11 & 100.00 \\
Barren1990 & 1.01 & 20.53 & 35.66 & $\mathbf{4 2 . 7 9}$ & 100.00 \\
\hline
\end{tabular}

The most notable agricultural abandonment occurred in the northwestern corner of La Gonave. Agricultural patches were abandoned and replaced by shrub lands (Figures 2 and 3). In the lowlands (where soils are often eroded to the bedrock), it is common to see the abandonment of agricultural lands after apparent soil exhaustion. Similar patterns and processes were found by [40] in Pic Macaya National Park in the Southwest region of the Haitian mainland. Between 1987 and 2004 the authors found a $17 \%$ decline in agriculture and the abandoned land reverted to herbaceous cover. For this island setting, informal interviews with local residents suggested that erosion, intensified by burning of lowland grasses and clearance for charcoal, cause rapid depletion of soil nutrients.

For forest and dense vegetation cover, $62.52 \%$ of Forest/DV pixels show as no-change. The majority of forest change can be attributed to 'forest-shrub' conversion (27.47\%). The tree felling activities are mainly family and individual-based, leading to sparse forest cover in certain locations. This process can be considered as partial deforestation related to selective logging. The shrub cover showed the highest percentage $(75.17 \%)$ of stable pixels from 1990 to 2010 . Shrub land was also 
converted to the Forest/DV class at a rate that was much slower than "forest-shrub" change. This slower conversion rate characterized overall forest degradation across the 1990-2010 study period. The Barren/Eroded class showed a $7.0 \%$ decrease of total area; it is notable that $56.2 \%$ of the Barren/Eroded land area in 1990 has been revegetated (Table 3). Most of the revegetated regions were spatially scattered at low elevations. Since our study used widely spaced temporal sampling points (i.e., 1990 and 2010), some areas might have experienced land cover changes (e.g., vegetation regrowth following clear-cutting) between the two sampling points. These land changes cannot be characterized through decadal image change analysis.

Figure 2. Land cover classification maps for La Gonave, Haiti, 1990 and 2010.

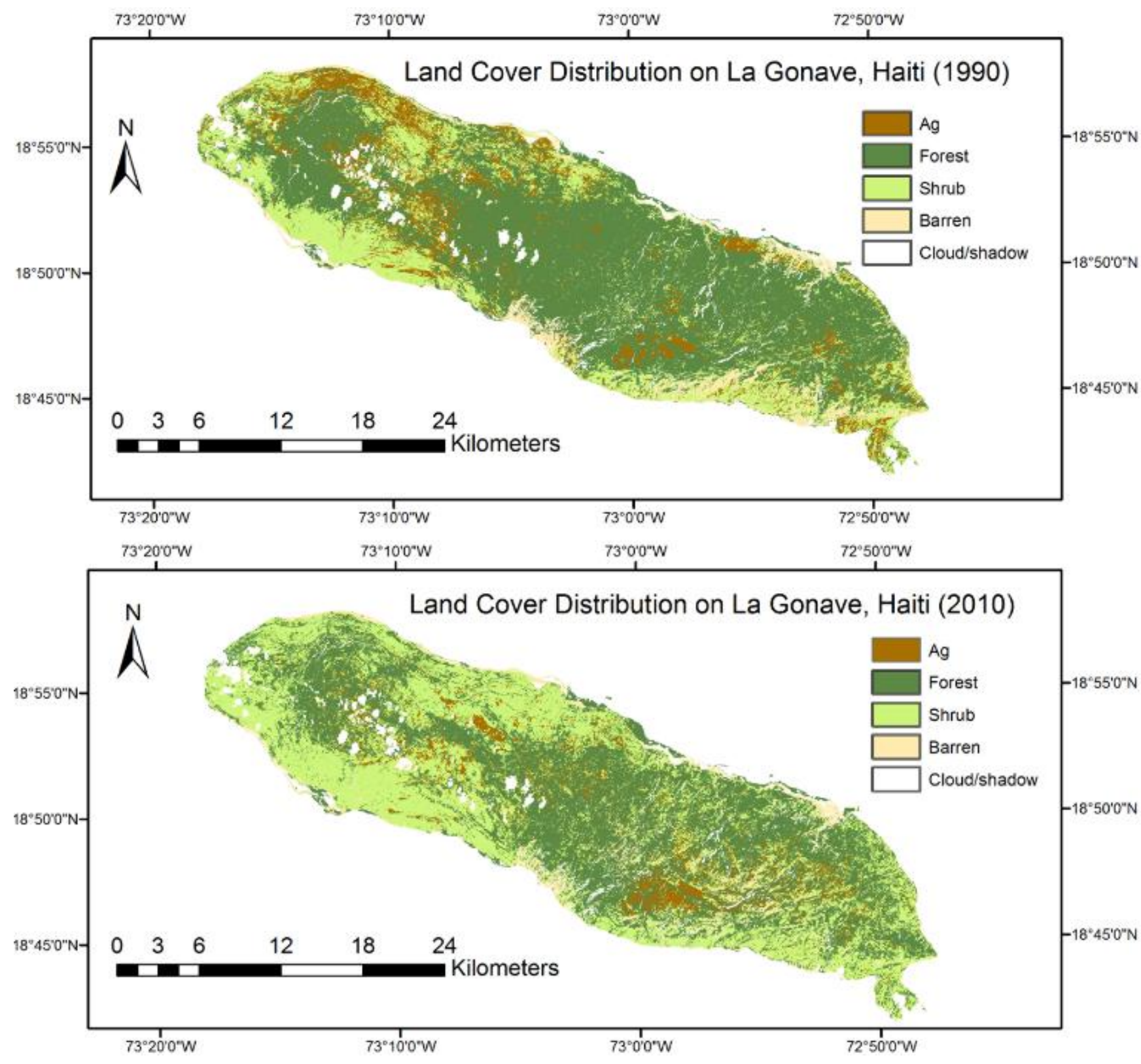


Figure 3. Agricultural areas converted to Forest/Dense Vegetation (DV). The most noticeable agricultural abandonment can be seen in the northwestern corner of La Gonave.

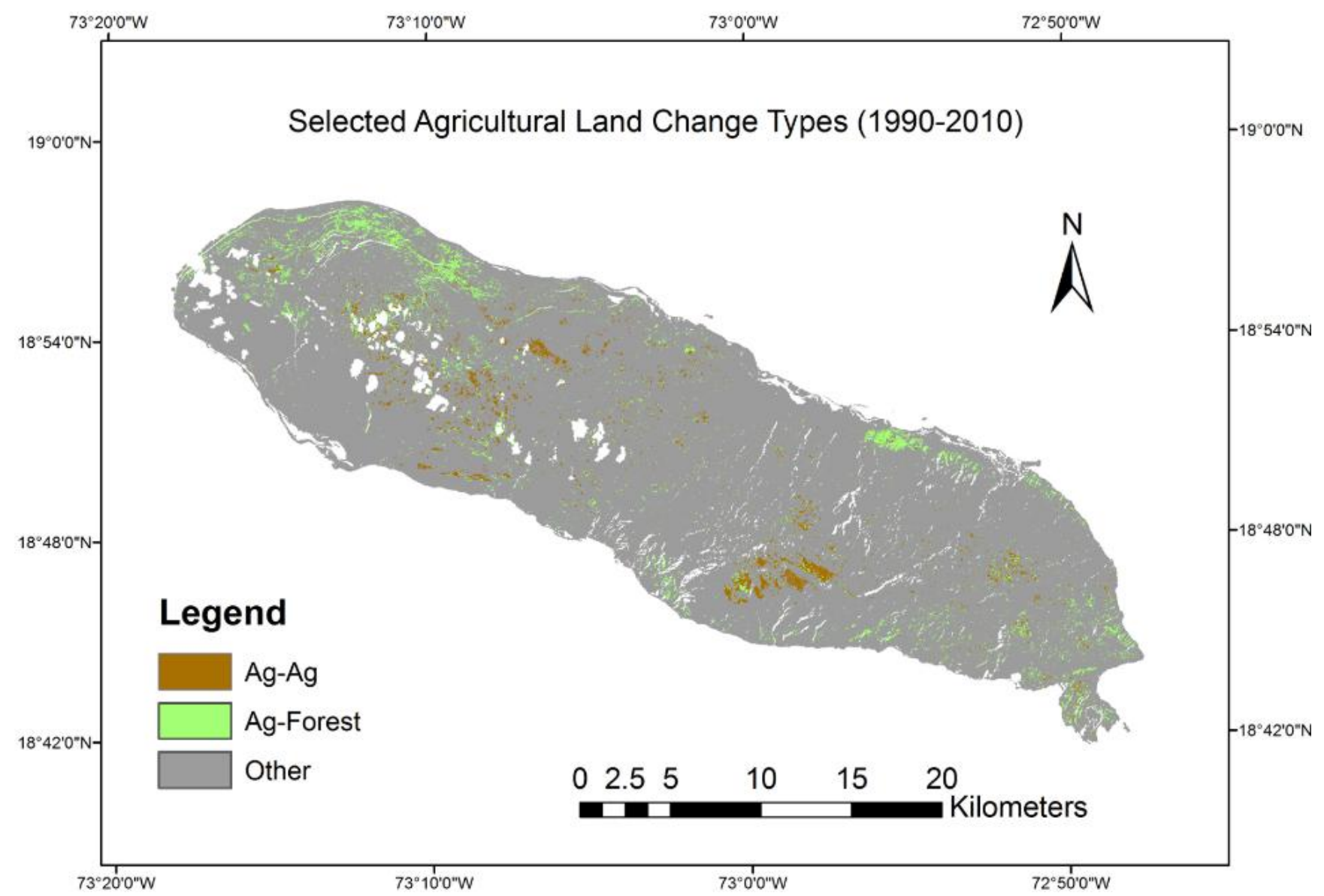

\subsection{Landscape Pattern Analysis}

A number of landscape pattern indices were calculated to improve our understanding of land cover dynamics (Table 4). All pattern indices for the Forest/DV class illustrated a decline in the class integrity. A 37\% decrease in largest patch area, a decrease in total area and mean patch size, and an increase in patch number. The fragmentation of the Forest/DV class in 2010 showed many linear or elongated patches. Exposing large amounts of patch edge can prevent conservation of a forest's internal resource [41] and structure. As the Forest/DV class became more fragmented it was largely replaced by the Shrub class. Commonly an increase in patch number represents fragmentation, however, the Shrub class increased in patch number $(+12 \%)$ and mean patch size; the largest patch size also doubled compared to the 1990 landscape. Many of these increases represent the large areas that converted to Shrub cover from Forest/DV and Agriculture.

Agricultural land was the most fragmented among the four cover classes. For the time period of 1990-2010, the total agricultural patch number decreased from 9,234 to 8,102. The average patch size decreased from 0.009 to $0.006 \mathrm{~km}^{2}$. Visual interpretation of land cover maps suggest that there was agricultural expansion near Plaine des Mapou: most are relatively smaller patches established on cleared forest lands. 
Table 4. Landscape pattern metrics/indices for the years 1990 and 2010 (PN = patch number, MP = mean patch area, LP = largest patch size).

\begin{tabular}{cccccc}
\hline & Year & Total Area $\left(\mathbf{k m}^{2}\right)$ & PN & MP $\left(\mathbf{k m}^{\mathbf{2}}\right)$ & $\mathbf{L P}\left(\mathbf{k m}^{\mathbf{2}}\right)$ \\
\hline Forest/DV & 1990 & 389.61 & 4557 & 0.085 & 357.52 \\
& 2010 & 314.43 & 4655 & 0.068 & 259.65 \\
Agriculture & 1990 & 80.91 & 9234 & 0.009 & 12.32 \\
& 2010 & 49.10 & 8102 & 0.006 & 5.24 \\
Shrub & 1990 & 142.28 & 7454 & 0.019 & 40.04 \\
& 2010 & 265.85 & 8362 & 0.032 & 86.45 \\
Barren/Eroded & 1990 & 46.73 & 3710 & 0.013 & 11.13 \\
& 2010 & 39.75 & 4202 & 0.009 & 16.61 \\
\hline
\end{tabular}

Segregating the land cover percentage change by elevation strata revealed important results (Figure 4). The decrease of agricultural land was most prominent at the lower elevations, ranging from the first to the fifth elevation strata. The Agriculture class showed a positive change for the remaining strata. The sharp percentage change near strata 12-15 indicates the conversions which occurred on steep highland slopes and the associated plateaus. More broadly, this pattern represents the movement of agricultural land from the lowlands to the highlands where it is concentrated away from areas of exposed limestone substrate. Forest/DV cover shows negative percent change across all elevation strata. The highest percentage change (+28\%) for Shrub class occurred at the second elevation strata, corresponding to the Shrub-Forest/DV transition zone. Barren/Eroded cover was relatively stable compared to other classes at lower elevation strata (i.e., $1-7)$, but there was also a peak value $(+10 \%)$ at strata 12 .

Figure 4. Class-level percentage change stratified by elevation depicting overall trends from base elevations to island peaks.

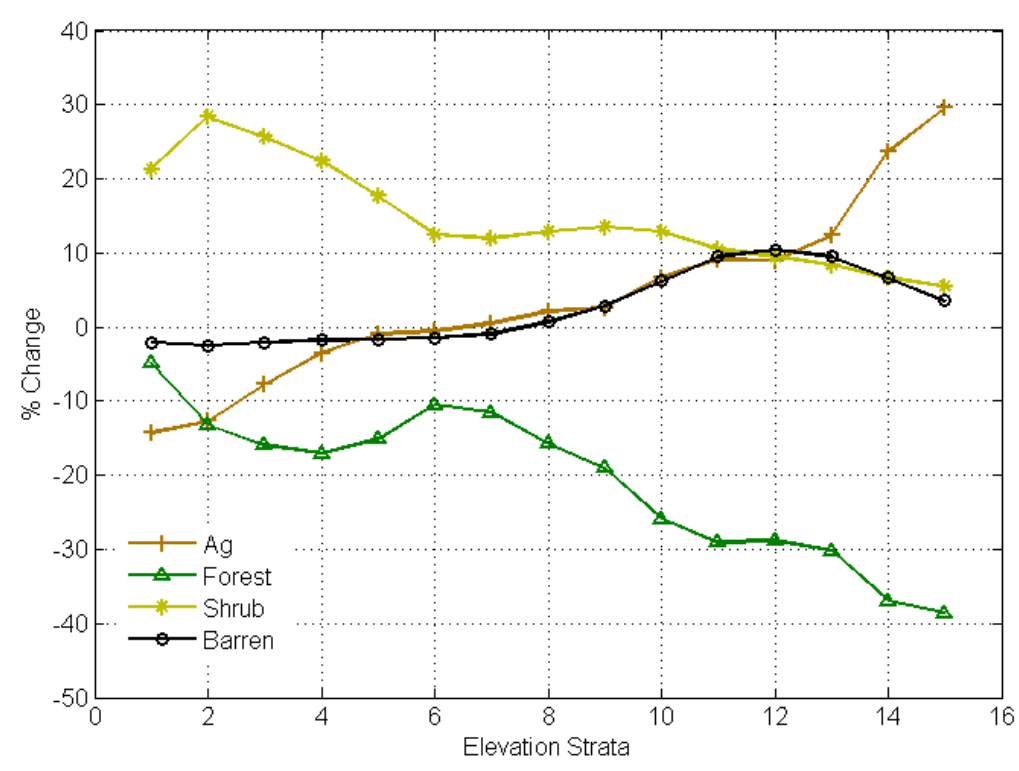

\section{Discussion}

The major pattern of landscape change revealed by our study of La Gonave is a decline in agricultural and forested area. Land clearance for agriculture was not a major cause of environmental 
degradation. This is partly because of the low population density and seasonal food production on La Gonave (as discussed by farmers residing in villages islandwide). These findings correspond with [42] who found that agriculture on the Haitian mainland was not highly responsible for degradation since it comprises a low proportion of total area.

There is strong evidence on La Gonave indicating that previously cleared areas in the lowlands (regions of poor soil nutrients derived from limestone regolith and limited soil horizons) are beginning to revegetate initially with xerophytic species as agricultural land is abandoned after soil exhaustion. This process was discussed as a common experience in informal interviews with farmers on La Gonave. Similar abandonment was found by [40,42] in Pic Macaya National Park in the Southwest region of the Haitian mainland. Between 1987 and 2004 the authors calculated a 17\% decline in agriculture and subsequent reversion of abandoned lands to herbaceous cover.

The majority of Forest/DV cover remains at higher elevations partly because the increased soil fertility results in more private land consequently protecting the flora, and the lower elevations make timber harvest/transport to the mainland more feasible. Currently on La Gonave, the primary tool used in woody material harvest is a simple, often damaged handsaw. We documented that the remaining substantial forest patches are in extremely rugged areas. The largest trees are on private lands and are commonly preserved for their fruit production, shade providing abilities, or spiritual value.

Revegetation on La Gonave is primarily illustrated by the increase in Shrub cover. Though shrub was the second largest land cover type in 2010, field observations indicate that the majority of the Shrub class cover varied along the scrub-dense vegetation gradient. Revegetated areas are composed of secondary succession forest, predominantly Acacia species maturing from shrub to grove. Woody shrubs are regularly harvested for charcoal production and for export roughly at the pole stage. This process is well studied by [43] who discussed the role of woody material derived from both forest and shrub cover in Haiti's charcoal production. A large portion of the residents' financial income on La Gonave is supported by the charcoal export to the mainland. The shrub cover may be caught in a perpetual cycle of harvest and revegetation rarely reaching early succession or the pole stage in growth. Future research should specifically document the ecological changes specifically in environments where charcoal harvest is currently occurring.

Field validation of image classification was challenging in mountainous regions. A two-year gap exists between our end-point 2010 image and our field data collection owing to image availability, budget and time constraints, and other challenges. Land cover conversions (e.g., selective logging, vegetation re-growth) within the two-year period may cause some confusion in the accuracy assessment of image classification, but we expect that the two-year land conversions were relatively subtle in this remote and sparsely populated setting. Assessing the map accuracy with field validation methods complemented by high resolution photographs enabled our research to obtain sufficient reference data points. The main challenge to the study of tropical land cover change remains to be lack of remote sensing data and related geo-spatial dataset. Cloud cover prevented this study from having multiple anniversary dates within the 20 year period, thus more detailed land cover change (e.g., land change trajectory) analysis was not possible.

It is important to note that some land cover conversions may have been omitted because of the spatial resolution of the satellite imagery and concealment by the tree canopy layer [44]. The land cover types are highly fractured; frequently with multiple land cover classes existing within a single 
pixel. Subtle land cover conversions (i.e., sub-pixel changes) were not considered in this study. In addition, with the 20-year anniversary images, certain agricultural changes and patterns might be overlooked. Considering external factors such as nationwide famine, levels of international food aid, cholera outbreaks, drought and other extreme weather events, there could be fluctuations in the agricultural patterns that are missed or misrepresented. Farmers may rotate fields in and out of production based on field fertility and socioeconomic conditions. Having only two anniversary images (20 years apart) may exacerbate or dampen the change results.

Future research could be implemented by using a higher temporal frequency of medium-high spatial resolution image sets. There are also data availability issues with regard to existence of social, geo-spatial, or forms of political, transportation, and topographic ancillary data for Haiti. Ancillary data such as crop type and yield, population fluctuations, climate records, timber extraction for sale, and land use history would provide important context for the processes and patterns occurring [45]. These data would also enable the quantification of the specific driving forces behind both land cover and land use changes.

\section{Conclusions}

We developed and analyzed land cover maps of La Gonave, Haiti using Landsat images from 1990 and 2010 to examine patterns of land cover change over the past two decades. Accuracy assessment, through field validation and aerial photo interpretation, indicated an overall accuracy of 2010 image classification was $87 \%$ with a kappa coefficient of 0.84 . Substantial changes had occurred including percentage area changes of $-39.73,-22.69,87.37$, and -7.04 , respectively, in Agricultural land, Forest/DV, Shrub, and Barren/Eroded. The processes of agricultural abandonment, deforestation, and forest regrowth combined to generate a dynamic island landscape, resulting in increasingly higher levels of land cover fragmentation. Overall, the abandonment of agricultural land appears to be driven by soil erosion and land mismanagement. Deforestation is mainly accomplished through tree felling by families and individuals for charcoal production. These land change patterns will likely continue in the context of competition for resources on this island, where economic desperation and the need for immediate income are paramount. Deliberate actions to create a healthier ecological state on the island are unlikely to occur unless the government can offer financial or resource incentives directly to residents.

\section{Conflicts of Interest}

The authors declare no conflict of interest.

\section{References}

1. Houghton, R.A. Tropical Deforestation as a Source of Greenhouse Gas Emissions. In Tropical Deforestation and Climate Change; Moutinho, P., Schwartzman, S., Eds.; Environmental Defense: Belem, Brazil, 2005; pp. 13-21.

2. Lambin, E.F.; Geist, H.J.; Lepers, E. Dynamics of land-use and land-cover change in tropical regions. Annu. Rev. Environ. Resour. 2003, 28, 205-241. 
3. Lambin, E.F.; Turner, B.L.; Geist, H.; Agbola, S.; Angelsen, A. The causes of land-use and land-cover change: Moving beyond the myths. Glob. Environ. Chang. 2001, 11, 261-269.

4. Cramer, W.; Bondeau, A.; Schaphoff, S.; Lucht, W.; Smith, B.; Sitch, S. Tropical forests and the global carbon cycle: Impacts of atmospheric carbon dioxide, climate change and rate of deforestation. Philos. Trans. R. Soc. Lond. B 2004, 359, 331-343.

5. Laurance, W.F. Reflections on the tropical deforestation crisis. Biol. Conserv. 1999, 91, 109-117.

6. Lal, R. Deforestation and land-use effects on soil degradation and rehabilitation in western nigeria. Land Degrad. Dev. 1997, 8, 95-126.

7. Foley, J.A.; DeFries, R.; Asner, G.P.; Barford, C.; Bonan, G.; Carpenter, S.R.; Chapin, F.S.; Coe, M.T.; Daily, G.C.; Gibbs, H.K.; et al. Global consequences of land use. Science 2005, 309, 570-574.

8. Metzger, M.J.; Rounsevell, M.D.A.; Leemans, R.; Schroter, D. The vulnerability of ecoystem services to land use change. Agric. Ecosyst. Environ. 2006, 114, 69-85.

9. Skole, D.; Tucker, C. Tropical deforestation and habitat fragmentation in the amazon: Satellite data from 1978 to 1988. Science 1993, 260, 1905-1910.

10. Walsh, S.J.; Crawford, T.W.; Crews-Meyer, K.A.; Welsh, W.F. A multi scale analysis of land use land cover change and NDVI variation in Nang Rong District, Northeast Thailand. Agric. Ecosyst. Environ. 2001, 85, 47-64.

11. Walsh, S.J.; Shao, Y.; Mena, C.F.; McCleary, A.L. Integration of hyperion satellite data and a household social survey to characterize the causes and consequences of reforestation patterns in the northern ecuadorian amazon. Photogramm. Eng. Remote Sens. 2008, 74, 725-735.

12. Rindfuss, R.R.; Walsh, S.J.; Turner, B.L.; Fox, J.; Mishra, V. Developing a science of land change: Challenges and methodological issues. Proc. Natl. Acad. Sci. USA 2004, 101, 13976-13981.

13. Food and Agriculture Organization (FAO). An Interim Report on the State of Forestry Resources in the Developing Countries; Food and Agriculture Organization (FAO): Bloomington, IN, USA, 1988.

14. Dolisca, F.; Mcdaniel, J.; Teeter, L.; Jolly, C. Land tenure, population pressure, and deforestation in Haiti: The case of forêt des pins reserve. J. For. Econ. 2007, 13, 277-289.

15. Lea, J.D. A Review of Literature on Charcoal in Haiti. In Proposis: Semiarid Fuelwood and Forage Tree. Building Consensus for the Disenfranchised; Center Semi-Aridforest Resources Publication: Kingsville, TX, USA, 1996.

16. Woodring, W.P.; Brown, J.S.; Burbank, W.S. Geology of the Republic of Haiti; The Lord Baltimore Press: Baltimore, MD, USA, 1924.

17. Franz, R.; Gicca, D.F. Observations on the Haitian snake antillophis parvifrons alleni. J. Herpetol. 1982, 16, 419-420.

18. Hadden, R.L.; Minson, S.G. The Geology of Haiti: An Annotated Bibliography of Haiti's Geology, Geography and Earth Science; Army Geospatial Center, US Army Corps of Engineers: Alexandria, VA, USA, 2010.

19. Institut Haïtien de Statistique et d'Informatique (IHSI). Statistiques Démographiques et Sociales; Departement de L'Ouest, Ministere de L'Economie et Des Finances: Port-au-Prince, Haiti, 2003.

20. World Vision Australia. Haiti: Thousands Flee to la Gonave to Seek Food and Shelter; World Vision Australia: Melbourne, Australia, 2010. 
21. Songe, C.; Woodcock, C.E.; Seto, K.C.; Lenney, M.P.; Macomber, S.A. Classification and change detection using Landsat TM data when and how to correct atmospheric effects? Remote Sens. Environ. 2001, 75, 230-244.

22. United States Geological Survey. Hazards Data Distribution Systems (HDDS); US Geological Survey: Sioux Falls, SD, USA, 2011.

23. Anderson, J.R.; Hardy, E.E.; Roack, J.T.; Witmer, R.E. A Land Use and Land Cover Classification System of use with Remote Sensor Data; United States Government Printing Office: Washington, DC, USA, 1976.

24. Weng, Q. Land use change analysis in the Zhujiang delta of china using satellite remote sensing, GIS and stochastic modelling. J. Environ. Manag. 2002, 64, 273-284.

25. Congalton, R. A review of assessing the accuracy of classifications of remotely sensed data. Remote Sens. Environ. 1991, 37, 35-46.

26. Shrestha, D.; Zinck, A. Land use classification in mountainous areas: Integration of image processing, digital elevation data and field knowledge (application to Nepal). Int. J. Appl. Earth Obs. Geoinf. 2001, 3, 78-95.

27. Smits, P.C.; Dellapiane, S.G.; Schowengerdt, R.A. Quality assessment of image classic cation algorithms for land-cover mapping: A review and a proposal for a cost-based approach. Int. J. Remote Sens. 1990, 20, 1461-1486.

28. Cochran, W.G. Sampling Techniques; Wiley: New York, NY, USA, 1977.

29. Stehman, S.V. Estimating the kappa coefficient and its variance under stratified random sampling. Photogramm. Eng. Remote Sens. 1996, 62, 401-402.

30. Singh, A. Review article digital change detection techniques using remotely-sensed data. Int. J. Remote Sens. 1989, 10, 989-1003.

31. Liu, H.; Zhou, Q. Accuracy analysis of remote sensing change detection by rule-based rationality evaluation with post-classification comparison. Int. J. Remote Sens. 2004, 25, 1037-1050.

32. Yuan, F.; Sawaya, K.; Loeffelholz, B.; Bauer, M. Land cover classification and change analysis of the twin cities (Minnesota) metropolitan area by multitemporal Landsat remote sensing. Remote Sens. Environ. 2005, 98, 317-328.

33. Turner, M.G. Landscape ecology: The effect of pattern on process. Annu. Rev. Ecol. Syst. 1989, 20, 171-197.

34. Gustafson, E.J. Quantifying landscape spatial pattern: What is the state of the art? Ecosystems 1998, $1,143-158$.

35. Luck, M.; Wu, J. A gradient analysis of urban landscape pattern: A case study from the Phoenix metropolitan region, Arizona, USA. Landsc. Ecol. 2002, 17, 327-339.

36. Millington, A.C.; Velez-Liendo, X.M.; Bradley, A.V. Scale dependence in multitemporal mapping of forest fragmentation in Bolivia: Implications for explaining temporal trends in landscape ecology and applications to biodiversity conservation. ISPRS J. Photogramm. Remote Sens. 2003, 57, 298-299.

37. McGarigal, K.; Marks, B.J. Fragstats: Spatial Pattern Analysis Program for Quantifying Landscape Structure; US Department of Agriculture, Forest Service, Pacific Northwest Research Station: Portland, OR, USA, 1993. 
38. Riitters, K. Assessing habitat suitability at multiple scales: A landscape-level approach. Biol. Conserv. 1997, 81, 191-202.

39. Tischendorf, L. Can landscape indices predict ecological processes consistently? Landsc. Ecol. 2001, 16, 235-259.

40. Vital, J.A. Land Use/Cover Chang Using Remote Sensing and Geographic Information Systems: Pic Macaya National Park, Haiti; Michigan Technological University: Houghton, MI, USA, 2008.

41. Forman, R.T. Some general principles of landscape and regional ecology. Landsc. Ecol. 1995, 10, 133-143.

42. Bal, Z.G.; Dent, D.L.; Olsson, L.; Schaepman, M.E. Global Assessment of Land Degradation and Improvement: Identification by Remote Sensing; United Nations Food and Agriculture Organization-International Soil Reference and Information Center (FAO-ISRIC): Wageningen, The Nethernlands, 2008.

43. Stevenson, G.G. The production, distribution, and consumption of fuelwood in Haiti. J. Dev. Area. 1989, 24, 59-77.

44. Peres, C.; Barlow, J.; Laurance, W. Detecting anthropogenic disturbance in tropical forests. Trends Ecol. Evol. 2006, 21, 227-229.

45. Read, J.M.; Denslow, J.S.; Guzman, S.M. Documenting land cover history of a humid tropical environment in northeastern coasta Rica using time-series remotely sensed data. GIS Remote Sens. Appl. Biogeogr. Ecol. 2001, 626, 69-89.

(C) 2013 by the authors; licensee MDPI, Basel, Switzerland. This article is an open access article distributed under the terms and conditions of the Creative Commons Attribution license (http://creativecommons.org/licenses/by/3.0/). 